\title{
Microvascular Decompression Versus Stereotactic Radiosurgery for Trigeminal Neuralgia: A Decision Analysis
}

Ian Berger $^{1}$, Nikhil Nayak ${ }^{2}$, James Schuster ${ }^{2}$, John Y. Lee ${ }^{3}$, Sherman Stein ${ }^{2}$, Neil R. Malhotra $^{2}$

1. School of Medicine, University of Pennsylvania School of Medicine, Philadelphia, PA 2. Neurological Surgery, University of Pennsylvania School of Medicine, Philadelphia, PA 3. Neurological Surgery, University of Pennsylvania School of Medicine, Philadelphia, PA, Philadelphia, USA

$\square$ Corresponding author: Neil R. Malhotra, nrm@uphs.upenn.edu Disclosures can be found in Additional Information at the end of the article

\section{Abstract}

Introduction: Both microvascular decompression (MVD) and stereotactic radiosurgery (SRS) have been demonstrated to be effective in treating medically refractory trigeminal neuralgia. However, there is controversy over which one offers more durable pain relief and the patient selection for each treatment. We used a decision analysis model to calculate the health-related quality of life (QOL) for each treatment.

Methods: We searched PubMed and the Cochrane Database of Systematic Reviews for relevant articles on MVD or SRS for trigeminal neuralgia published between 2000 and 2015. Using data from these studies, we modeled pain relief and complication outcomes and assigned QOL values. A sensitivity analysis using a Monte Carlo simulation determined which procedure led to the greatest QOL.

Results: MVD produced a significantly higher QOL than SRS at a seven-year follow-up. Additionally, MVD patients had a significantly higher rate of complete pain relief and a significantly lower rate of complications and recurrence.

Conclusions: With a decision-analytic model, we calculated that MVD provides more favorable outcomes than SRS for the treatment of trigeminal neuralgia.

Received 10/27/2016

Review began 10/28/2016 Review ended 01/15/2017 Published 01/26/2017

\section{(c) Copyright 2017}

Berger et al. This is an open access article distributed under the terms of the Creative Commons Attribution License CC-BY 3.0., which permits unrestricted use, distribution, and reproduction in any medium, provided the original author and source are credited.
Categories: Neurology, Neurosurgery

Keywords: trigeminal neuralgia, microvascular decompression, radiosurgery, gamma knife, cyberknife, decision analysis

\section{Introduction}

Trigeminal neuralgia (TN) is a debilitating condition characterized by unilateral stabbing facial pain along the divisions of cranial nerve V. The lifetime prevalence of TN is estimated to be 0.7 per 1,000 people and usually presents between the fourth and seventh decades [1]. First line management involves medical therapy, although 10-25\% of patients fail to respond to standard medication regimens and some patients may become resistant to medical treatment over time [2]. For patients with medically refractory TN, there are a number of proven invasive treatments. Approximately 8,000 patients undergo surgical treatment for TN in the U.S. annually with a total societal cost of over $\$ 100$ million [3]. MVD is the most common surgical 
procedure performed for TN in the U.S.; however, the use of Gamma Knife (Elekta AB, Stockholm, Sweden) surgery has been increasing worldwide [4]. Unfortunately, many patients that undergo surgery experience a recurrence of symptoms after treatment, which further complicates the management of TN.

Microvascular decompression is a common nondestructive surgical approach used to treat medically refractory TN [5]. Approximately 80\% of MVD patients experience immediate pain relief, with $75 \%$ and $64 \%$ maintaining relief after one year and 10 years, respectively [5]. However, age, degree of pain, medical comorbidies, previous procedures, or patient preferences may preclude the use of MVD [6]. Less invasive techniques such as SRS aim to lesion the nerve in order to achieve pain control. SRS avoids the operative risk of MVD and patients are usually discharged the same day. However, the pain recurrence rate is greater than $20 \%$ at five years, and the results appear less durable than MVD [7]. Other modalities of radiosurgery, such as linear accelerator-based radiosurgery, have been shown to be effective and safe in observational studies, but limited prospective data exists [8].

There is limited data to support treatment selection algorithms in choosing MVD or SRS in cases of clinical equipoise, where either procedure is a viable option [9]. Both surgeon and patient preferences preclude adequately powered trials. Only a few direct comparison studies between MVD and SRS exist in the literature, and none contain a random assignment of patients [7, 10-11]. In many studies, cohorts are operated on by a single surgeon, who likely has significant experience in that surgery. Complication rates from MVD are lower when the procedure is performed at a high-volume hospital or by a high-volume surgeon [12].

Additionally, there is much heterogeneity in reporting outcomes in TN [13]. Differences in pain scales and follow-up time hinder the direct comparison between studies and often leave the results open to interpretation. Commonly used outcomes such as pain-free and recurrence rates are influenced by complications. There are very few studies that report health-related quality of life (HRQoL) utility scores. If complication rates vary between MVD and SRS, then HRQoL should also differ between the procedures and may not be embodied by conventional metrics.

Here we present a decision analysis model for the treatment of trigeminal neuralgia comparing MVD and SRS using postoperative outcomes and complication data from the published literature. Our study aims to provide evidence for the selection of treatment, which will maximize quality of life for patients suffering from this disease.

\section{Materials And Methods}

\section{Model}

We constructed a decision-analytic model of outcomes following treatment for trigeminal neuralgia and related facial pain syndromes, using either MVD or SRS. The base case is a patient with uncontrolled pain despite maximal medical therapy. Reports in which atypical facial pain constituted a majority of the cases were omitted. The possible pathways and outcomes after treatment are shown in Figure 1. Either procedure can be associated with postprocedure complications or be complication free. We have modeled four possible pain outcomes, based on the Barrow Neurological Institute (BNI) Pain Intensity Score (Table 1). Once treatment occurs, the pain may recur (at a BNI level of III to V), and repeat treatment may be required. 


\section{Cureus}

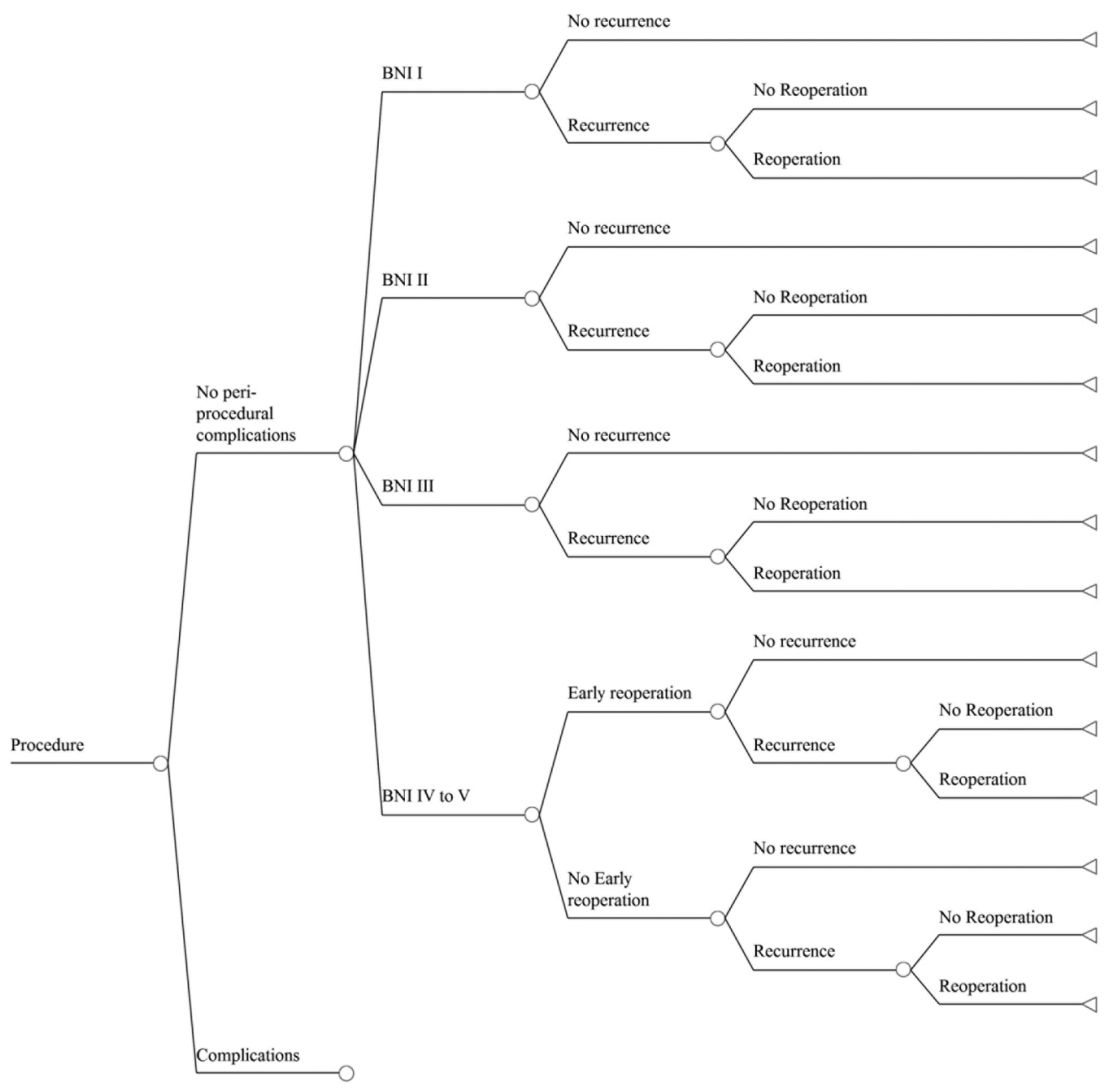

\section{FIGURE 1: Outcomes of the Surgical Treatment of Trigeminal}

\section{Neuralgia}

Decision tree outlining the possible pathways encountered by a patient undergoing either SRS or MVD for trigeminal neuralgia. Note that because of the very large number of branches contained in the entire tree, we only display outcomes of a single procedure, free of complications. The tree shown is repeated for cases in which complications occur, and this larger tree is repeated for the other procedure. The aggregate tree is then populated with the probability of each branch and the effect on quality of life for each outcome. 


\section{Cureus}

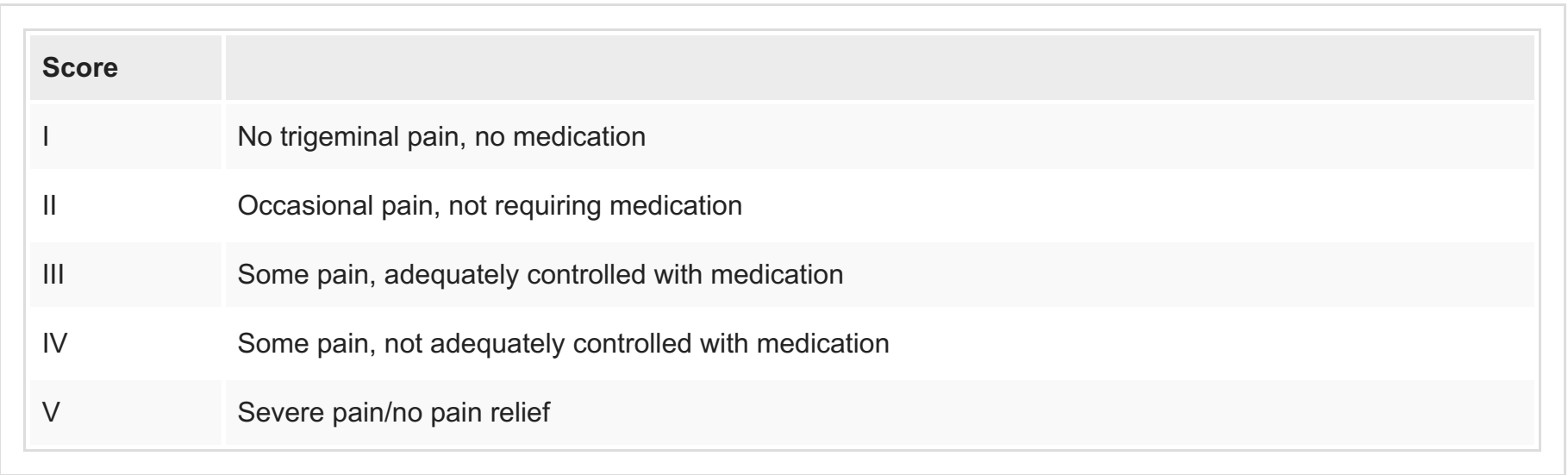

\section{TABLE 1: Barrow Neurological Institute Pain Intensity Score}

Patient reported pain intensity score for TN developed by the BNI [14].

The model enters the probability of each possible outcome illustrated in Figure 1, as well as the effect of each outcome on HRQoL, as measured by utility [15]. A utility score is a parametric measure of a patient's preference for a given health outcome in the face of uncertainty. A patient carries the utility associated with her/his BNI score, requirement or not of taking medications, and any complications associated with a procedure. The expected utility of each branch is found by multiplying the branch's probability by the utility of the final outcome. Rollback analysis, the process that is used to calculate the expected utility of each branch and to add the resulting products for a given treatment strategy, produces the expected utility of that strategy. The expected utilities of two or more strategies thus represent their relative impacts on a patient's QOL and are directly comparable.

Complications occurring in fewer than one percent of cases were omitted unless they had great impact on QOL (e.g. stroke and death). Transient complications, which have negligible effect on outcome, particularly after lengthy follow-up, are also not included. The model assumes that all cases in which pain recurs, does so after 2.5 years and has BNI scores of IV-V after pain returns. Patients who chose to re-treat their pain were limited to two additional procedures. Total quality-adjusted life years (QALYs) for the follow-up period were calculated by adding the QALYs of each year. For example, seven years in perfect health would equal seven QALYs.

\section{Literature search}

We searched PubMed and the Cochrane Database of Sytematic Reviews for all publications between January 2000 and June 2015 for relevant articles. We performed multiples searches with the main subject headings "facial neuralgia" or "facial pain," plus either a single subheading or title term. The subheadings used were "treatment," "surgery," or "radiotherapy," and the the title terms used were "microvascular," "radiosurgery," "radiosurgical," "gamma," "Linac," "Cyberknife," "Accuray," or "X knife." A similar search was performed to determine the QOL corresponding to each outcome in the model. We limited our review to English language publications containing at least 10 treated cases.

\section{Data management}

We abstracted estimates of complications, outcomes by BNI scores, utilities, recurrence, and reoperation rates from our search. Since most case series included patients with and without previous treatment, we included only publications in which fewer than $35 \%$ of cases had 
previous SRS or MVD. Not every article reported data for every category. Articles missing data for a category were excluded from the analysis of that category. Data was pooled metaanalytically [16] to calculate the probability of each outcome; the reported point estimates of data represent inverse variance-weighted means, which were tested to exclude heterogeneity [17]. The types and frequencies of complications are different after SRS and MVD. Since this is also true for several other parameters, we calculated their expected utilities using sub-trees. We examined outcomes at one- and seven-year follow-ups. Although some MVD studies follow patients for more than ten years, no SRS publication averages much longer than seven years. Recurrence rates, which vary with duration of follow-up, were determined by meta-regression for each follow-up time studied [18]. Meta-analysis and meta-regression employ random effects models. To factor in the effect of follow-up time, we reported outcomes at various follow-up durations as QALYs, a measure that combines both aspects [19]. Perfect health $(\mathrm{QOL}=1)$ times one year of life equals one QALY; likewise, QOL of 0.25 times four years of life equals one QALY.

\section{Analysis}

We used data obtained by literature review and pooled as above to populate our decision tree. Our primary analysis compared the two treatments with respect to expected QALYs after primary treatment. We performed sensitivity analysis using a two-dimensional Monte Carlo simulation (expected QALYs for 100 simulated trials, each made up of 100 microsimulations) [20]. We employed beta distributions for all probabilities and utilities. We calculated pooled demographic data, such as mean ages, gender distribution, and previous procedures, for the two treatment groups.

Because the events after MVD and SRS occur at different times after treatment, the model assumes that the post-treatment BNI state occurs immediately after MVD but, on average, at one month after SRS. Re-treatment for therapeutic failures occurs at one and three months after primary treatment for MVD and SRS, respectively. The wait is to allow for possible delayed effects of the initial therapy. Similarly, treatment complications are assumed to occur immediately after MVD and an average time of six months after SRS. Keeping with standard decision-analytic practice, QOL associated with multiple outcomes is calculated by multiplying the utilities of each [21]. For example, in a subject with BNI III and surgical complications after MVD, the expected utility would equal the utility of MVD complications times the utility of BNI III times the utility of requiring medication. Random effects meta-regression models were used to investigate recurrence rates and relationships between treatment type, demographic variables (age, gender, length of follow-up, and previous pain procedures), and outcome. Since it was impractical to run the decision-analytic model separately for each case series and calculate QALYs associated with each, we elected to use the percentage of cases with posttreatment BNI scores of I as our primary measure of successful outcome. We also looked at rates of failure (BNI score = IV-V), complications, and recurrence.

Comparisons of expected utilities at each time point used t-tests, and probabilities of $<0.05$ were considered significant. Meta-analytic pooling, meta-regressions, and statistical analyses were done with inverse-variance-weighted random effects models using Stata 12 (StataCorp LP, College Station, TX). Analyses of the model, including Monte Carlo simulation, employed TreeAge Pro 2012 (TreeAge Software, Inc., Williamstown, MA).

\section{Results}

\section{Literature search}

The search yielded 2,246 publications. After rejecting unsuitable abstracts and excluding publications without useful data, there were 57 publications including 8,484 cases remaining, which form the basis for our analysis. Search results are shown in Figure 2. The characteristics of these studies are presented in Table 2 . 


\section{Cureus}

$2246 \quad$ Abstracts reviewed

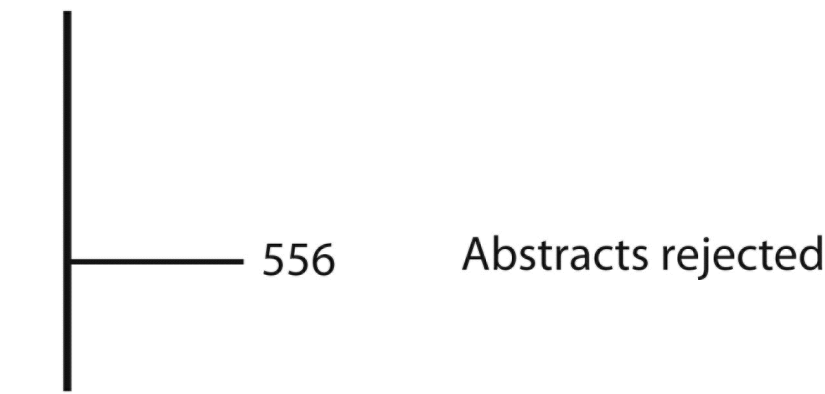

1692 Publications downloaded and read

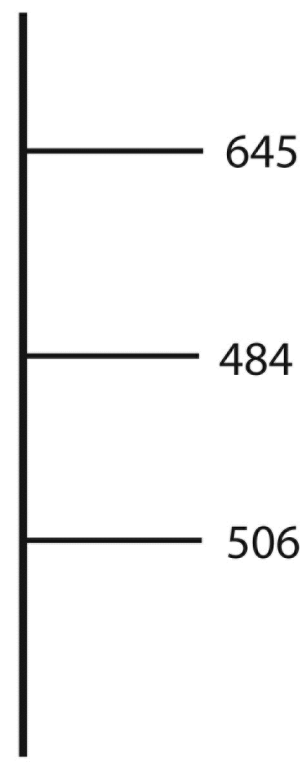

Not English, nonsurgical treatment, laboratory investigations

Too few cases, too many with prior procedures, results not BNI scale, etc.

Lacked original data (review,technical report, duplicated data, editorial, letter)

57 Articles used for this report

FIGURE 2: Articles Reviewed

Summary of abstracts and articles reviewed for this report. Reasons for the rejection of case series are shown.

\begin{tabular}{|c|c|c|c|}
\hline First Author & Type of Procedure & Number of Cases & Study Type \\
\hline Brisman [22] & SRS & 49 & Observational \\
\hline Nicol [23] & SRS & 42 & Observational \\
\hline Chang [24] & SRS & 15 & Observational \\
\hline Shaya [25] & SRS & 40 & Observational \\
\hline Lim [26] & SRS & 41 & Observational \\
\hline Tawk [27] & SRS & 38 & Observational \\
\hline
\end{tabular}




\section{Cureus}

\begin{tabular}{|c|c|c|c|}
\hline Pollock [28] & Both & 83 & Prospective Cohort study \\
\hline Massager [29] & SRS & 109 & Observational \\
\hline Fountas [30] & SRS & 77 & Observational \\
\hline Balamucki [31] & SRS & 172 & Observational \\
\hline Fountas [32] & SRS & 57 & Observational \\
\hline Longhi [33] & SRS & 92 & Observational \\
\hline Brisman [34] & SRS & 61 & Observational \\
\hline Lorenzoni [35] & SRS & 89 & Observational \\
\hline Matsuda [36] & SRS & 100 & Observational \\
\hline Huang [37] & SRS & 89 & Observational \\
\hline Linskey [11] & Both & 70 & Prospective Cohort study \\
\hline Oh [38] & Both & 45 & Retrospective comparison \\
\hline Dhople [39] & SRS & 112 & Observational \\
\hline Knafo [40] & SRS & 67 & Observational \\
\hline $\operatorname{Han}[41]$ & SRS & 51 & Observational \\
\hline Fariselli [42] & SRS & 33 & Observational \\
\hline Adler [43] & SRS & 46 & Observational \\
\hline Park [44] & SRS & 39 & Observational \\
\hline Chen [45] & SRS & 40 & Observational \\
\hline Sheehan [46] & SRS & 63 & Observational \\
\hline Hayashi [47] & SRS & 130 & Observational \\
\hline Park [48] & SRS & 17 & Observational \\
\hline Park [49] & SRS & 62 & Observational \\
\hline Tuleasca [50] & SRS & 497 & Observational \\
\hline Fraioli [51] & SRS & 23 & Observational \\
\hline Attia [52] & SRS & 19 & Observational \\
\hline Lee [53] & SRS & 91 & Observational \\
\hline Flickinger [54] & SRS & 174 & Observational \\
\hline Lazzara [55] & SRS & 16 & Observational \\
\hline Young [56] & SRS & 250 & Observational \\
\hline Lee [57] & SRS & 21 & Observational \\
\hline
\end{tabular}




\section{Cureus}

Lucas [58]

SRS

Observational

Song [59]

SRS

Observational

$\mathrm{Xu}$ [60]

SRS

99

Observational

Tyler-Kabara [61]

MVD

Observational

Ashkan [62]

MVD

80

Observational

Olson [63]

MVD

156

Observational

Zakrzewska [64]

MVD

220

Observational

Aryan [65]

MVD

Observational

Sindou [6]

MVD

362

Observational

Laghmari [66]

MVD

Observational

Tarricone [67]

MVD

20

Observational

Bond [68]

MVD

Observational

Oesman [69]

MVD

120

Observational

Chakravarthi $[70]$

MVD

Observational

Chen [71]

MVD

Observational

Zhong [72]

MVD

1274

Observational

Sandel [73]

MVD

243

Observational

Reddy [74]

MVD

60

Observational

Shibahashi [75]

MVD

Observational

Sarnvivad [76]

MVD

98

Observational

\section{TABLE 2: Publications Used in This Analysis}

Publications used in the analysis arranged by publication date.

\section{Patient characteristics}

Table 3 demonstrates the demographic differences between the two treatments. Compared to MVD, patients undergoing SRS are significantly more likely to be older. Follow-up in MVD patients is significantly longer. The trend of more SRS patients having undergone a previous facial pain procedure approaches significance, and sex distribution is the same in the two groups. 


\section{Cureus}

\begin{tabular}{|c|c|c|c|c|c|c|c|}
\hline \multirow{2}{*}{ Characteristic } & \multicolumn{3}{|l|}{ SRS } & \multicolumn{3}{|l|}{ MVD } & \multirow{2}{*}{ Difference ( $p$-value) } \\
\hline & $\mathrm{N}$ & Mean & SD & $\mathrm{N}$ & Mean & SD & \\
\hline$\%$ Female & 3144 & 60.9 & 8.0 & 1699 & 62.7 & 8.0 & 0.462 \\
\hline Mean Age & 1944 & 67.6 & 4.5 & 3697 & 57.5 & 3.3 & $<0.001$ \\
\hline Mean Follow-up (mos) & 3477 & 31.7 & 19.2 & 3697 & 43.2 & 27.6 & 0.065 \\
\hline \% With Previous Procedures & 3013 & 21.1 & 10.4 & 3387 & 14.9 & 10.8 & 0.058 \\
\hline
\end{tabular}

\section{TABLE 3: Patient Characteristics}

\section{Comparative effectiveness}

Probabilities and utilities of possible outcomes for the tree (Figure 1) are summarized in Table 4 and Table 5, respectively. Cure of pain (BNI score of I) is significantly more likely after MVD; poor pain control, complications, and recurrences are significantly lower after MVD than SRS. The sorts of complications encountered after either SRS or MVD are shown in Table 6, along with the utility of each. When complications occur, their impact on QOL does not depend on surgical approach $(\mathrm{p}=0.850)$.

\begin{tabular}{|c|c|c|c|c|c|}
\hline \multirow{2}{*}{ Outcome } & \multicolumn{2}{|l|}{ SRS } & \multicolumn{2}{|l|}{ MVD } & \multirow{2}{*}{ Difference (p-value) } \\
\hline & Mean & SD & Mean & SD & \\
\hline \multicolumn{6}{|l|}{ BNI score (\%) } \\
\hline 1 & 38.8 & 17.5 & 52.8 & 21.3 & 0.01 \\
\hline II & 20.9 & 10.8 & 26.2 & 24.5 & 0.256 \\
\hline III & 25.5 & 12.7 & 13.3 & 5.1 & $<0.001$ \\
\hline IV-V & 14.8 & 6.4 & 7.7 & 0.67 & $<0.001$ \\
\hline Complications (\%) & 19.3 & 0.7 & 17.6 & 0.5 & $<0.001$ \\
\hline 7-year recurrence rate (\%) & 22.6 & 13.4 & 15.9 & 10.5 & 0.013 \\
\hline Recurrences re-treated (\%) & 45.5 & 35.5 & 8.0 & 6.9 & 0.005 \\
\hline
\end{tabular}

TABLE 4: Probabilities of Outcomes After Treatment 


\section{Cureus}

\begin{tabular}{|c|c|c|c|}
\hline Description & Utility & SD & Ref \\
\hline BNI I & 1.0 & $\mathrm{~N} / \mathrm{A}$ & Hunink 2001 [21] \\
\hline BNI II & 0.871 & 0.213 & Perez et al. 2009 [77] \\
\hline BNI III & 0.739 & 0.221 & Perez et al. 2009 [77], Spatz et al. 2007 [78] \\
\hline BNI IV-V & 0.399 & 0.189 & Perez et al. 2009 [77] \\
\hline Complications after MVD & 0.958 & 0.013 & Calculated from analysis (Table 7) \\
\hline Complications after SRS & 0.962 & 0.085 & Calculated from analysis (Table 8) \\
\hline Needing to take medication & 0.881 & 0.003 & Calculated from analysis (Table 9) \\
\hline Re-treatment by MVD & 0.915*(utility MVD) & N/A & Lega et al. 2010 [79] \\
\hline Re-treatment by SRS & $0.915^{\star}$ (utility SRS) & N/A & Lega et al. 2010 [79] \\
\hline
\end{tabular}

\section{TABLE 5: Utilities of Outcomes After Treatment of Trigeminal Neuralgia by MVD or}

SRS

$\mathrm{N} / \mathrm{A}=$ not appropriate 


\section{Cureus}

\begin{tabular}{|c|c|c|c|}
\hline Name & $\begin{array}{l}\text { Mean } \\
\text { Utility }\end{array}$ & SD & Ref \\
\hline No complications & 1.0 & 0 & Hunink 2001 [21] \\
\hline CSF leak & 0.985 & NR & Estimate \\
\hline Facial palsy & 0.983 & 0.018 & Whitmore et al. 2011: Vestibular schwannoma [80] \\
\hline Corneal keratitis & 0.963 & NR & van de Graaf et al. 2010 [81] \\
\hline $\begin{array}{l}\text { Facial numbness, paresthesia, or } \\
\text { dysesthesia }\end{array}$ & 0.960 & 0.014 & Whitmore et al. 2011: Vestibular schwannoma [80] \\
\hline Meningitis & 0.930 & 0.030 & Whitmore et al. 2011: Vestibular schwannoma [80] \\
\hline Unilateral deafness & 0.929 & 0.110 & Whitmore et al. 2011: Vestibular schwannoma [80] \\
\hline Acute subdural hematoma & 0.868 & .0170 & Lega et al. 2010: Chronic SDH [79] \\
\hline Diplopia & 0.762 & 0.104 & Hatt et al. 2010 [82] \\
\hline Stroke & 0.5 & NR & Samsa et al. 1999 [83] \\
\hline Perioperative death & 0 & 0 & Hunink 2001 [21] \\
\hline
\end{tabular}

\section{TABLE 6: Effect of Periprocedural Complications on Utility}

CSF = cerebrospinal fluid; NR $=$ not reported

Table 7 shows complication rates following MVD. Individual procedure-related complications are assumed to add. The total perioperative complication rate is $13.3 \%$. With the decision tree shown in Figure 3, the expected utility of patients with complications after MVD is $0.958 \pm$ 0.013 . 


\section{Cureus}

\begin{tabular}{llll}
\hline Complication & Mean & SD \\
\hline Facial numbness & 0.044 & 0.020 \\
\hline Facial palsy & 0.011 & 0.017 \\
Perioperative death & 0.002 & 0.001 \\
Deafness & 0.018 & 0.030 \\
CSF leak & 0.013 & 0.021 \\
Meningitis, wound infection & 0.012 & 0.016 \\
\hline Other complications & 0.033 & 0.005
\end{tabular}

TABLE 7: Incidence of Complications After MVD for Trigeminal Neuralgia CSF $=$ cerebrospinal fluid 


\section{Cureus}

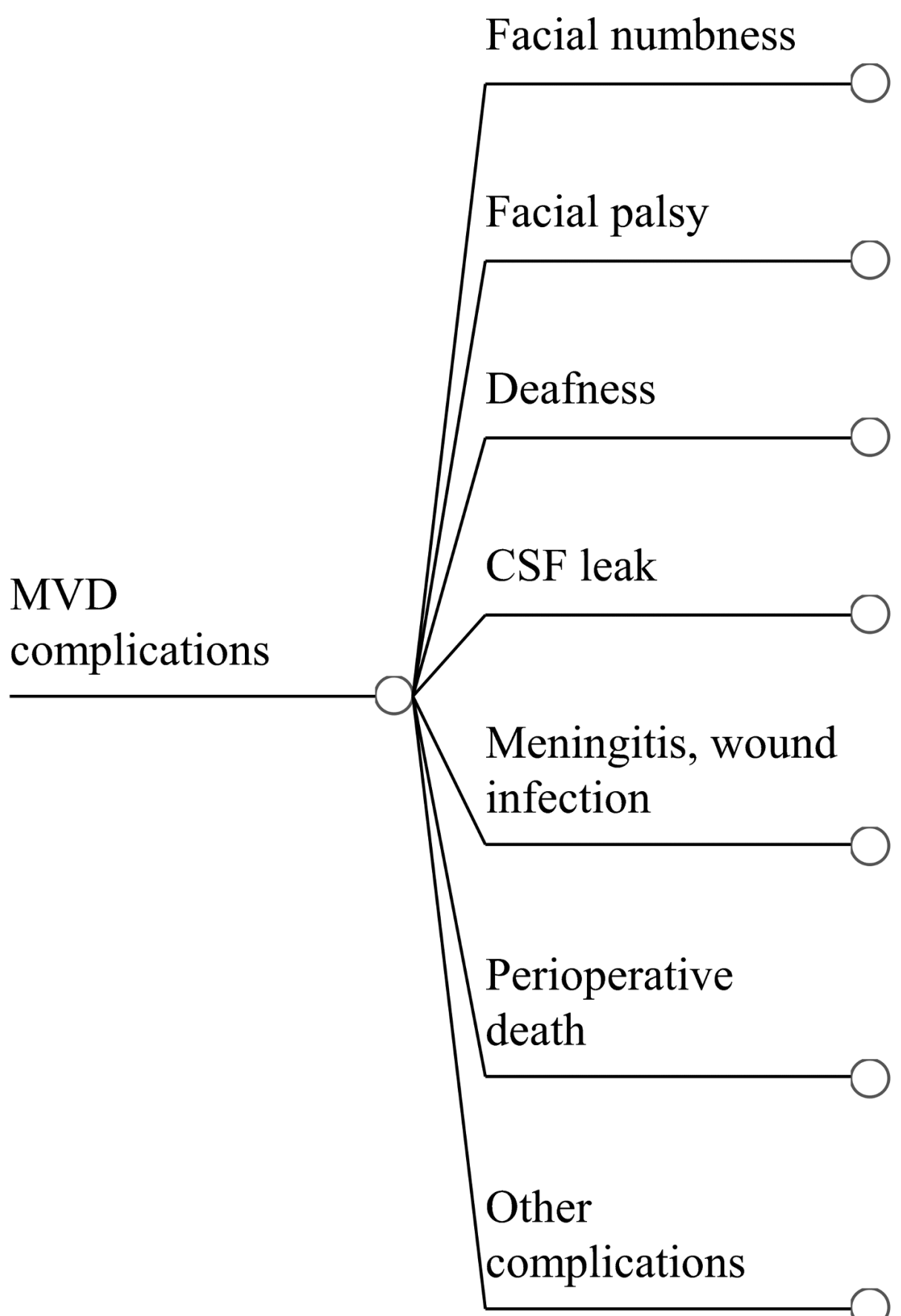

FIGURE 3: Complications of MVD Treatment

Sub-tree outlining complications reported after MVD for trigeminal neuralgia.

Table 8 summarizes the complication rates for patients undergoing SRS for TN. The sole exception to the addition of individual complications is keratitis, in which patients are assumed to also have trigeminal and facial nerve deficits. The total procedure-related complication rate is $19.3 \%$. Figure 4 is a decision tree to calculate expected utility for patients encountering complications after SRS, which was found to be $0.962 \pm 0.085$. 


\section{Cureus}

\section{Complication}

Facial numbness

Facial palsy

Corneal keratitis

Hypertension, other complications

\section{TABLE 8: Incidence of Complications After SRS for Trigeminal Neuralgia}

\section{Facial numbness}

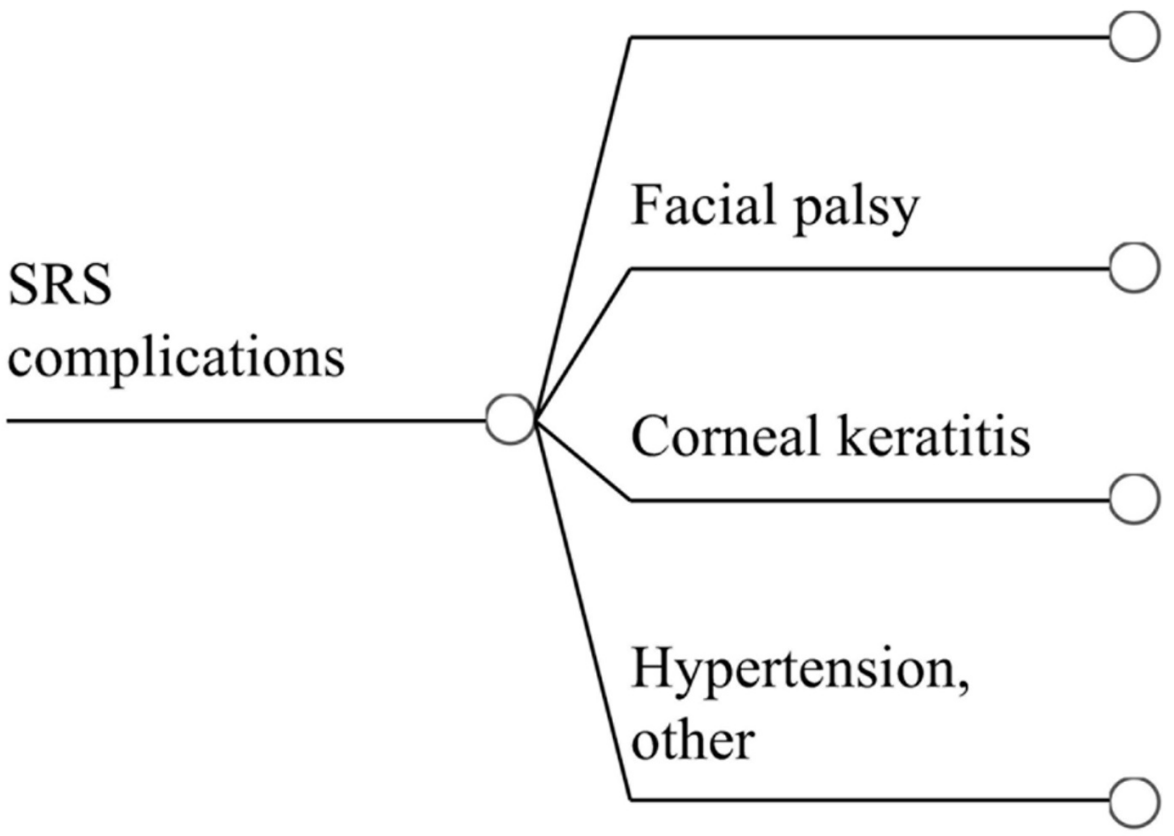

\section{FIGURE 4: Complications of SRS Treatment}

Sub-tree outlining complications reported after SRS for trigeminal neuralgia. Populating the tree with the probability and utility associated with each complication permits calculation of expected utility in patients who suffer complications after SRS.

Taking medicine several times daily has a modest impact on QOL. However, the presence of complications associated with its use can have severe repercussions. Table 9 reports probabilities and associated utilities of different severities of medication complications. Analysis of the decision tree (Figure 5) employing these values yielded an expected utility of $0.881 \pm 0.003$. 


\section{Cureus}

\section{Description}

Probability

no medication complications

mild-moderate medication complications

severe medication complications

Utility

mild-moderate medication complications

severe medication complications

0.912

SD

0.092

0.144

0.126

0.774

0.148

\section{TABLE 9: Probability and Utility of Trigeminal Neuralgia Medication Side Effects}

Values based on a decision analysis by Spatz et al. examining which treatments for TN offer the best patient quality of life [78].

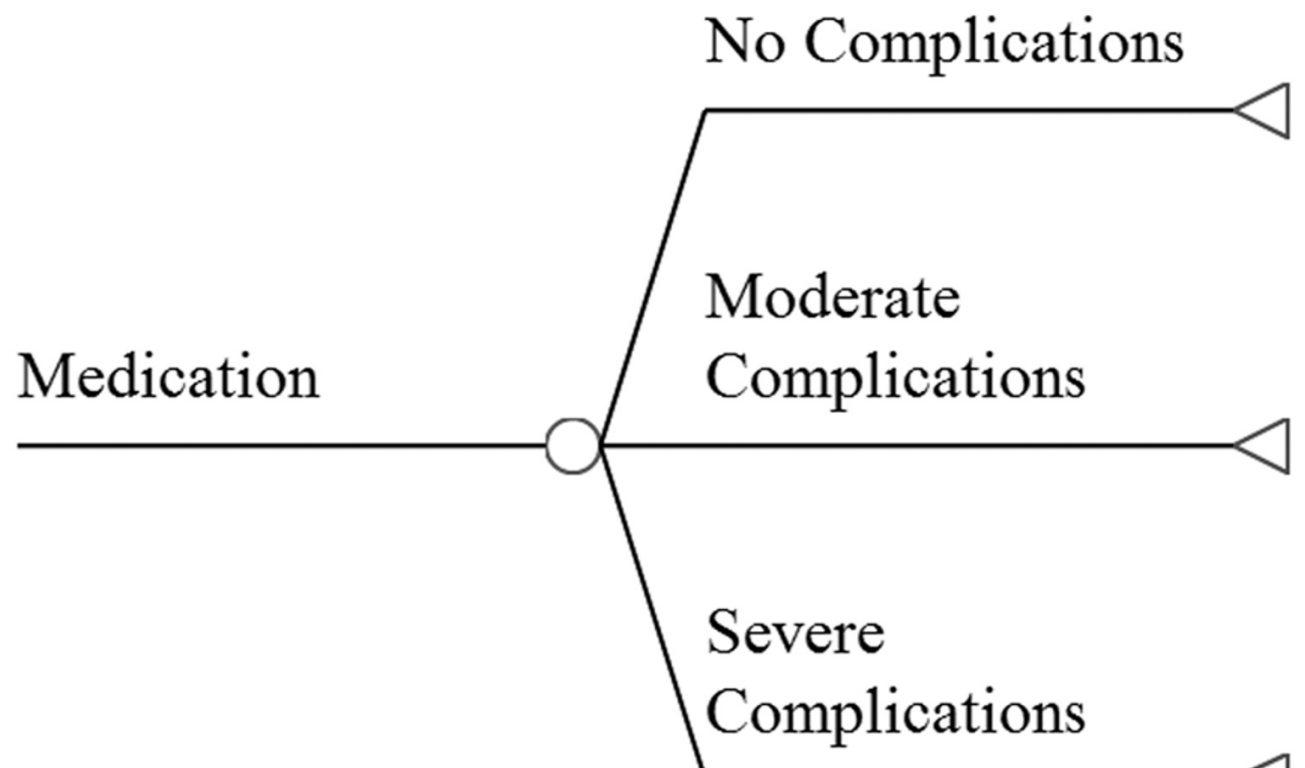

FIGURE 5: Outcomes of Medical Treatment

Sub-tree for calculating the expected utility of taking maintenance medication.

Meta-regressions of recurrence rates after SRS and MVD failed to suggest an increasing recurrence rate with the passage of time ( $p=0.597$ and 0.492 , respectively). Meta-analysis was 
therefore used to calculate seven-year recurrence rates for SRS and MVD. The results are reported in Table 4. The model assumes that all recurrences occur midway in the follow-up period, and pain recurrences not requiring surgical (radiosurgical) procedures are all BNI level III. Treatment modality for failure of primary treatment or recurrence is based on the proportions of procedure types reported in the literature. SRS cases with recurrence tended to involve MVD for recurrences; failed MVD cases were followed by a second MVD in $80 \%$ of cases. The small number of percutaneous reoperations were not included in the analysis, as they had minimal impact on outcome.

We calculated expected QOL at seven years after the pain procedure. MVD outcomes (6.009 \pm 0.173 QALYs) are significantly higher $(\mathrm{p}<0.001)$ than those with SRS $(5.411 \pm 0.132$ QALYs). The higher utility of MVD is attributable in part to its higher initial success rate and lower pain recurrence rate compared to SRS.

Meta-regression of outcomes against demographic factors revealed only a few near-significant correlations shown in Table 10. For MVD patients, success (post-procedure BNI I) was inversely related to age. There was a near-significant inverse trend in the SRS group between prior procedures and success, and a trend in MVD patients between prior procedures and complication rate. Recurrence rate did not increase significantly over time after either procedure. 


\section{Cureus}

\begin{tabular}{|c|c|c|c|c|c|c|c|c|}
\hline \multirow{3}{*}{ Predictor variable } & \multicolumn{8}{|c|}{ Outcome variable } \\
\hline & \multicolumn{2}{|c|}{ success rate ${ }^{1}$} & \multicolumn{2}{|c|}{ failure rate ${ }^{2}$} & \multicolumn{2}{|c|}{ complication rate } & \multicolumn{2}{|c|}{ recurrence rate } \\
\hline & $\mathrm{R}^{2}$ & $\mathrm{p}$-value & $R^{2}$ & $p$-value & $R^{2}$ & $\mathrm{p}$-value & $\mathrm{R}^{2}$ & $p$-value \\
\hline \multicolumn{9}{|l|}{ SRS } \\
\hline Age & $<0.01$ & 0.599 & $<0.01$ & 0.906 & $<0.01$ & 0.820 & $<0.01$ & 0.768 \\
\hline Sex & 0.012 & 0.248 & 0.023 & 0.584 & 0.024 & 0.210 & 0.029 & 0.585 \\
\hline Follow-up (mos) & \multicolumn{8}{|c|}{ not measured } \\
\hline Prior Procedure & 0.074 & 0.051 & 0.001 & 0.353 & 0.106 & 0.071 & 0.075 & 0.108 \\
\hline \multicolumn{9}{|l|}{ MVD } \\
\hline Age & 0.99 & 0.023 & 0.485 & 0.410 & $<0.01$ & 0.908 & $<0.01$ & 0.884 \\
\hline Sex & 0.034 & 0.649 & 0.059 & 0.901 & 0.099 & 0.901 & $<0.01$ & 0.524 \\
\hline Follow-up (mos) & \multicolumn{6}{|c|}{ not measured } & 0.022 & 0.492 \\
\hline Prior Procedure & 0.070 & 0.741 & 0.027 & 0.500 & 0.206 & 0.056 & 0.126 & 0.267 \\
\hline
\end{tabular}

\section{TABLE 10: Associations Among Predictor Variables and Outcomes}

Significant associations shown in bold.

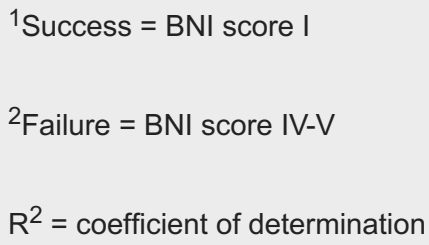

\section{Discussion}

TN commonly becomes refractory to medication and may require surgical intervention. There are many studies reporting successful outcomes of various procedures for $\mathrm{TN}$; however, the subjective nature of pain and lack of HRQoL data make comparisons difficult. The results of this study suggest MVD is significantly more likely to produce a BNI I outcome and result in greater QOL than SRS at a seven-year follow-up. MVD had significantly less complications and a lower recurrence rate at seven years. MVD success rates were inversely correlated with age.

\section{Microvascular decompression surgery}

Microvascular decompression is currently the most common surgical treatment for TN [84]. MVD procedures in the U.S. increased 194\% between the years of 1988 to 2008 [85]. While considered safe, MVD is a major neurosurgical procedure that carries some risk.

Many observational studies have found MVD to be an effective treatment for TN. Tatli et al. [86] 
conducted a review of all surgical treatments for TN, including 16 studies for MVD in which the average follow up was 6.7 years. Pain-free rates at last follow-up were $76.6 \%$, and the average recurrence rate was $18.4 \%$ at last follow-up. They also found the rates of facial numbness at one to two percent. Our analysis found that MVD resulted in a lower rate of BNI I outcomes (52.8\% at seven years). However, Tatli et al. noted that the results of many of the observational studies were up to interpretation. Our rate of BNI II was very high (26.2\%), and it is possible that this group of patients was included in the "treatment success" group in Tatli's review. We found a recurrence rate of $15.9 \%$, which is similar to the $18.4 \%$ reported by Tatli [86]. Recurrence can occur because of compression of the nerve from the interposing material placed during surgery or recontact of a vessel with the nerve. A “sling” technique may be used to hold the vessel off the nerve, and it demonstrates promise at lowering recurrence rates despite its technical difficulty [87]. The most common reported complication of MVD in our study was facial numbness, affecting $4.4 \%$ of patients. This rate is higher than that reported by Tatli [86]. Some of our included studies did not distinguish between permanent numbness and transient or nonbothersome numbness, which may explain the higher rate. Our model found that complications from MVD were significantly higher if the patient had undergone a previous procedure, which is consistent with previous reports in the literature [88-89]. In a study of 305 hospitals from 1996 to 2000, it was reported that the mortality rate for MVD was $0.3 \%$, similar to $0.2 \%$ found in our study [12]. Mortality was associated with surgeons who performed relatively few MVDs.

MVD is an open surgical procedure that is associated with complications thought to be greater in elderly populations [90]. However, recent studies have shown that MVD can be just as effective and safe for elderly patients [62]. We found that age was inversely related to a BNI I after MVD. Thus, while age cannot be ruled out as an independent predictor of outcome for MVD, SRS may be the more effective treatment in the elderly.

Compared to SRS, MVD was shown to have better outcomes with regard to complete pain relief, lower complication rates, and recurrence rates. Additionally, the mean follow-up time for MVD studies, while not statistically significant, was longer, providing some evidence for the durability of the results. New techniques such as endoscopic MVD are reaching clinical practice and may further improve the safety of MVD for TN, although further outcomes research with endoscopic techniques are still needed [91].

\section{Stereotactic radiosurgery}

Radiosurgery has evolved dramatically with advancements in imaging allowing more precise targeting, devices allowing better delivery that spares the brainstem, and better clinical data to plan the most effective dose. There is a wide range (22-83\%) in the rates of pain-free outcomes from SRS reported in the literature [92-93]. This variability may have to do with the different follow-up periods of these studies, as outcomes from SRS have been shown to be much less durable than MVD [27]. According to a study by Pollock et al. [94], the risk of trigeminal nerve dysfunction is related to the dose of radiosurgery, and the author found that $50 \%$ of patients receiving a dose of $90 \mathrm{~Gy}$ experienced new dysfunction compared to $15 \%$ of those receiving 70 Gy. In a second study, he associated new dysfunction to decreasing treatment success rates [95]. Massager et al. noted that patients receiving higher doses of radiation to the brainstem experienced increased rates of facial numbness, although this was not significant in their study [96]. However, increased radiation doses delivered to the brainstem significantly predicted pain control.

Several studies have investigated the role of anterior or posterior targeting of the trigeminal nerve during SRS treatments. Matsuda et al. [36] found that targeting the dorsal root entry zone (DREZ) compared to the nerve proximal to the gasserian ganglion produced higher initial rates of pain relief and lower complication rates. However, Park et al. [44] found a decrease in time to response when targeting the retrogasserian zone compared to the DREZ. No differences in 
complication rates were found in this study. Within the DREZ, proximal targeting of the nerve may lead to decreased rates of recurrence, but an increased rate of new facial numbness [60]. While the use of one versus two isocenters does not seem to have an effect on pain relief, higher, but not statistically significant, rates of sensory loss were found in patients treated with two isocenters in a prospective, blinded trial performed by Flickinger et al. [97]. However, a separate study demonstrated increases in pain relief using two isocenters without increases in complication rate [98].

Parmar et al. noted in their review that, although SRS complication rates are significant, they have been improving over time, perhaps related to advances in imaging and dose delivery [99]. MRI images that use the thinnest slices and highest resolution lead to the most accurate surgeries with Gamma Knife [100]. Recurrence rates in the literature are between six and 41\% [101]. Patients that experience a recurrence in pain may undergo a second round of radiosurgery but at an increased risk to developing facial numbness [102].

The results of our study are consistent with the literature on outcomes for SRS. Our mean complete pain relief rate was $38.8 \%$, while we calculated a $22.6 \%$ recurrence rate at seven years. The largest morbidity for SRS in our study was facial numbness at $14.1 \%$. Cruccu et al. found, in a review for the American Academy of Neurology and European Federation of Neurological Societies (AAN-EFNS) guidelines, that facial numbness affects nine to $37 \%$ of patients in large studies [103], which was consistent with our findings. The higher rates of morbidity and recurrence limit the utility of SRS in treating TN. In our study, we found that SRS patients were older, and there was a trend toward significance of having had prior procedures. This finding is consistent with the often held view that SRS is reserved for older patients with recurrent pain. Due to its minimally invasiveness, it may be used to treat TN refractory to MVD [104]. However, the Maesawa et al. study noted that prior procedures were associated with a lower rate of complete pain relief [105].

The timing of re-treatment of TN with SRS after initial treatment failure is a topic of discussion. Initial pain-free rates increase dramatically within the first three months after treatment before plateauing at six months [106]. Thus, the decision to re-treat should be done at least six months, and often one year, after initial therapy. Our model cannot capture the variability that occurs in clinical practice and the uncertainty of treatment success that exists between therapy and the six-month decision to treat. Patients who are intially pain free may experience a brief relapse of pain that eventually dissipates. Therefore, in our model, patient response to therapy was determined at one month after treatment, and the decision to re-treat was done at three months. Furthermore, there is a subset of patients who are initially pain free that may develop a recurrence of pain, which then gradually subsides. This pathway was not included in our analysis, given the complexities of incorporating these patients into the model and the lack of literature on these patients.

\section{Comparative studies}

Several studies have compared the cost effectiveness of the surgical treatments for TN. Both Holland et al. [107] and Pollock et al. [3] conducted small studies in which they found that MVD produced a higher number of quality-adjusted pain-free years and was more cost effective than SRS. Sivakanthan et al. found that MVD produced a QALY gain of 8.2 at a five-year follow-up, while SRS was 4.9 QALYs gained [84]. With MVD at 6.0 and SRS at 5.4 QALYS, our study demonstrated a smaller discrepancy in QALYs gained than Sivakanthan. However, Sivakanthan's study only used one article each to calculate the QALYs for the treatments. Spatz et al. performed a decision analysis in 2007 comparing medical therapy, MVD, percutaneous glycerol rhizolysis, radiofrequency thermocoagulation, and balloon compression, using a cohort of 156 patients [78]. They concluded that MVD was the procedure most likely to maximize QOL; however, SRS was not included as a treatment modality. 
Two studies have looked at the impact of MVD and SRS on patient satisfaction and found that the durability of pain relief with MVD greatly influences patient satisfaction with the procedure compared to SRS $[7,11]$. However, they used a small number of patients, and adequate literature on patient satisfaction is lacking.

\section{Quality of studies and limitations}

The overall quality of the studies used in the decision analysis was generally poor when assessed individually. This had previously been noted in 2003 by Zakrewska et al. [108] and continues to hold true. Many articles used their own scales for treatment success and pain relief, leaving the results open to interpretation and hindering comparison. The overwhelming majority of the articles used in this analysis were observational, demonstrating the lack of randomized controlled trials in the literature for surgical treatments of trigeminal neuralgia. Most of the studies provided a description of the patient characteristics; however, preoperative pain, sensory loss, and medication dosages were frequently not included. Both outcome measures and complication rates were heterogeneous and in some instances, only vaguely identified. However, most studies reported recurrence rates within their follow-up window.

If each publication reported utility scores for patients before and after treatment, a direct comparison of utility change after SRS and MVD would be possible. Unfortunately, these scores are rarely obtained. Instead, our model assumes that a complication-free procedure, resulting in a BNI score of I, has a utility of one. Although the resulting utilities are not equivalent to scores reported in actual TN patients [77, 109], the relative utilities of the treatment groups remain the same. Thus, the calculated utilities accurately reflect the relative outcomes and permit valid statistical comparisons.

Our results must be interpreted with caution. The model makes several simplifying assumptions, any of which can impact our results. Our data arise from a series of indirect, nonrandomized comparisons, within which there is clinical heterogeneity. The studies analyzed varied with respect to patient selection, baseline severity of pain, treatment assignment, outcome parameters measured, and time of follow-up. The use of a random effects model partially compensates for heterogeneity but cannot completely correct for it. For example, the majority of TN studies fail to record the preoperative level of pain, preventing a comparison between pre- and post-treatment [108]. While there are clinical pain scales to correct this problem, they were not used in our analysis [110]. Our reliance on trial-level data, rather than individual patient information, may also introduce aggregation bias.

In addition to Monte Carlo simulations, we ran sensitivity analyses in which we systematically varied values of each major variable. None had a significant impact on our results except when varied to extreme values. We cannot rule out age as an independent predictor of outcome in MVD, suggesting SRS may be the more effective treatment in the elderly. There are nearsignificant trends linking prior procedures with lower success rates with SRS and with higher complication rates after MVD.

There are other limitations to our study. The HRQoL data we used is taken from the literature as a proxy to create a TN disease state rather than from individual patients. The values for perioperative complications are from different sources and are not specific to TN. Even so, our model assumes that the relative values can be compared between MVD and SRS. Additionally, complications in the literature are presented dichotomously and don't represent the duration or severity that could impact the measurement on QOL. For example, facial numbness was tracked in most of the studies, but the degree and distribution of numbness was not recorded and could have a variable impact on the treatment utility. Finally, surgery for medically refractory $\mathrm{TN}$ cannot be determined by a standard algorithm. Heterogeneity among patients precludes true clinical equipoise. Many of the included studies had cohorts that were operated 
on by a single surgeon. The effect of surgeon experience on outcome should not be underestimated in procedures such as MVD and cannot be accounted for by our model.

The results of this study aim to direct surgical decision-making for the treatment of medically refractory TN in cases where MVD and SRS are both suited. While surgeon and patient preference play a large role in decision-making, this study suggests that MVD provides a higher QOL than SRS, and that initial pain-free rates, recurrence rates, and complications play a large role in postoperative HRQoL. This study, and the observational studies it draws from, demonstrates the need for standardized, high-quality research to continue to explore the application of surgery to TN.

\section{Conclusions}

MVD for trigeminal neuralgia is associated with a significantly higher quality of life than SRS. This difference is primarily attributable to MVD's higher initial cure rate and lower recurrence rate. Although follow-up data for SRS does not permit comparison after seven years of followup, the trend toward rising recurrence rates following SRS suggests that the advantages of MVD are more durable.

\section{Additional Information Disclosures}

Human subjects: All authors have confirmed that this study did not involve human participants or tissue. Animal subjects: All authors have confirmed that this study did not involve animal subjects or tissue. Conflicts of interest: In compliance with the ICMJE uniform disclosure form, all authors declare the following: Payment/services info: All authors have declared that no financial support was received from any organization for the submitted work. Financial relationships: All authors have declared that they have no financial relationships at present or within the previous three years with any organizations that might have an interest in the submitted work. Other relationships: All authors have declared that there are no other relationships or activities that could appear to have influenced the submitted work.

\section{References}

1. MacDonald BK, Cockerell OC, Sander JW, Shorvon SD: The incidence and lifetime prevalence of neurological disorders in a prospective community-based study in the UK. Brain. 2000, 123:665-676. 10.1093/brain/123.4.665

2. Taylor JC, Brauer S, Espir ML: Long-term treatment of trigeminal neuralgia with carbamazepine. Postgrad Med J. 1981, 57:16-18. 10.1136/pgmj.57.663.16

3. Pollock BE, Ecker RD: A prospective cost-effectiveness study of trigeminal neuralgia surgery . Clin J Pain. 2005, 21:317-322.

4. Regis J, Tuleasca C: Fifteen years of Gamma Knife surgery for trigeminal neuralgia in the Journal of Neurosurgery: history of a revolution in functional neurosurgery. J Neurosurg. 2011, 115:2-7.

5. Barker FG, Jannetta PJ, Bissonette DJ, Larkins MV, Jho HD: The long-term outcome of microvascular decompression for trigeminal neuralgia. N Engl J Med. 1996, 334:1077-1084. 10.1056/NEJM199604253341701

6. Sindou M, Leston J, Decullier E, Chapuis F: Microvascular decompression for primary trigeminal neuralgia: long-term effectiveness and prognostic factors in a series of 362 consecutive patients with clear-cut neurovascular conflicts who underwent pure decompression. J Neurosurg. 2007, 107:1144-1153. 10.3171/JNS-07/12/1144

7. Nanda A, Javalkar V, Zhang S, Ahmed O: Long term efficacy and patient satisfaction of microvascular decompression and gamma knife radiosurgery for trigeminal neuralgia. J Clin Neurosci. 2015, 22:818-822. 10.1016/j.jocn.2014.11.028

8. Varela-Lema L, Lopez-Garcia M, Maceira-Rozas M, Munoz-Garzon V: Linear accelerator 
stereotactic radiosurgery for trigeminal neuralgia. Pain Physician. 2015, 18:15-27.

9. Zakrzewska JM, Akram H: Neurosurgical interventions for the treatment of classical trigeminal neuralgia. Cochrane Database Syst Rev. 2011, 9:CD007312.

10.1002/14651858.CD007312.pub2

10. Pollock BE, Schoeberl KA: Prospective comparison of posterior fossa exploration and stereotactic radiosurgery dorsal root entry zone target as primary surgery for patients with idiopathic trigeminal neuralgia. Neurosurgery. 2010, 67:633-639. 10.1227/01.NEU.0000377861.14650.98

11. Linskey ME, Ratanatharathorn V, Penagaricano J: A prospective cohort study of microvascular decompression and Gamma Knife surgery in patients with trigeminal neuralgia. J Neurosurg. 2008, 109:160-172.

12. Kalkanis SN, Eskandar EN, Carter BS, Barker FG 2nd: Microvascular decompression surgery in the United States, 1996 to 2000: mortality rates, morbidity rates, and the effects of hospital and surgeon volumes. Neurosurgery. 2003, 52:1251-1262. 10.1227/01.NEU.0000065129.25359.EE

13. Akram H, Mirza B, Kitchen N, Zakrzewska JM: Proposal for evaluating the quality of reports of surgical interventions in the treatment of trigeminal neuralgia: the Surgical Trigeminal Neuralgia Score. Neurosurg Focus. 2013, 35:3. 10.3171/2013.6.FOCUS13213

14. Rogers CL, Shetter AG, Fiedler JA, Smith KA, Han PP, Speiser BL: Gamma knife radiosurgery for trigeminal neuralgia: the initial experience of the Barrow Neurological Institute. Int J Radiat Oncol Biol Phys. 2000, 47:1013-1019. 10.1016/S0360-3016(00)00513-7

15. Sox HC, Blatt MA, Higgins MC, Marton KI: Medical Decision Making. American College of Physicians, Philadelphia; 2007 .

16. Einarson TR: Pharmacoeconomic applications of meta-analysis for single groups using antifungal onychomycosis lacquers as an example. Clin Ther. 1997, 19:559-569.

17. King JT Jr, Berlin JA, Flamm ES: Morbidity and mortality from elective surgery for asymptomatic, unruptured, intracranial aneurysms: a meta-analysis. J Neurosurg. 1994, 81:837-842. 10.3171/jns.1994.81.6.0837

18. Thompson SG, Higgins JP: How should meta-regression analyses be undertaken and interpreted?. Stat Med. 2002, 21:1559-1573. 10.1002/sim.1187

19. Pliskin JS, Shepard DS, Weinstein MC: Utility functions for life years and health status . Operations Research. 1980, 28:206-224. 10.1287/opre.28.1.206

20. Concato J, Feinstein AR: Monte Carlo methods in clinical research: applications in multivariable analysis. J Investig Med. 1997, 45:394-400.

21. Hunink MGM, Glasziou PP, et al.: Decision Making in Health and Medicine: Integrating Evidence and Values. Cambridge University Press, Cambridge, United Kingdom; 2001.

22. Brisman R: Gamma knife radiosurgery for primary management for trigeminal neuralgia . J Neurosurg. 2000, 93:159-161. 10.3171/jns.2000.93.supplement

23. Nicol B, Regine WF, Courtney C, Meigooni A, Sanders M, Young B: Gamma knife radiosurgery using 90 Gy for trigeminal neuralgia. J Neurosurg. 2000, 93:152-154.

24. Chang JW, Chang JH, Park YG, Chung SS: Gamma knife radiosurgery for idiopathic and secondary trigeminal neuralgia. J Neurosurg. 2000, 93:147-151.

25. Shaya M, Jawahar A, Caldito G, Sin A, Willis BK, Nanda A: Gamma knife radiosurgery for trigeminal neuralgia: a study of predictors of success, efficacy, safety, and outcome at LSUHSC. Surg Neurol. 2004, 61:529-534. 10.1016/j.surneu.2003.11.027

26. Lim M, Villavicencio AT, Burneikiene $S$, et al.: CyberKnife radiosurgery for idiopathic trigeminal neuralgia. Neurosurg Focus. 2005, 18:1-7.

27. Tawk RG, Duffy-Fronckowiak M, Scott BE, et al.: Stereotactic gamma knife surgery for trigeminal neuralgia: detailed analysis of treatment response. J Neurosurg. 2005, 102:442449. 10.3171/jns.2005.102.3.0442

28. Pollock BE: Comparison of posterior fossa exploration and stereotactic radiosurgery in patients with previously nonsurgically treated idiopathic trigeminal neuralgia. Neurosurg Focus. 2005, 18:1-4.

29. Massager N, Nissim O, Murata N, Devriendt D, Desmedt F, Vanderlinden B, Regis J, Levivier M: Effect of beam channel plugging on the outcome of gamma knife radiosurgery for trigeminal neuralgia. Int J Radiat Oncol Biol Phys. 2006, 65:1200-1205.

10.1016/j.ijrobp.2006.01.043

30. Fountas KN, Lee GP, Smith JR: Outcome of patients undergoing gamma knife stereotactic 
radiosurgery for medically refractory idiopathic trigeminal neuralgia: Medical College of Georgia's experience. Stereotact Funct Neurosurg. 2006, 84:88-96. 10.1159/000094366

31. Balamucki CJ, Stieber VW, Ellis TL, et al.: Does dose rate affect efficacy? The outcomes of 256 Gamma Knife surgery procedures for trigeminal neuralgia and other types of facial pain as they relate to the half-life of cobalt. J Neurosurg. 2006, 105:730-735.

10.3171/jns.2006.105.5.730

32. Fountas KN, Smith JR, Lee GP, Jenkins PD, Cantrell RR, Sheils WC: Gamma Knife stereotactic radiosurgical treatment of idiopathic trigeminal neuralgia: long-term outcome and complications. Neurosurg Focus. 2007, 23:7. 10.3171/FOC-07/12/E8

33. Longhi M, Rizzo P, Nicolato A, et al.: Gamma knife radiosurgery for trigeminal neuralgia: results and potentially predictive parameters--part I: idiopathic trigeminal neuralgia. Neurosurgery. 2007, 61:1254-1260.

34. Brisman R: Microvascular decompression vs. Gamma Knife radiosurgery for typical trigeminal neuralgia: preliminary findings. Stereotact Funct Neurosurg. 2007, 85:94-98.

10.1159/000097925

35. Lorenzoni JG, Massager N, David P, et al.: Neurovascular compression anatomy and pain outcome in patients with classic trigeminal neuralgia treated by radiosurgery. Neurosurgery. 2008, 62:368-376. 10.1227/01.neu.0000316003.80893.81

36. Matsuda S, Serizawa T, Nagano O, Ono J: Comparison of the results of 2 targeting methods in Gamma Knife surgery for trigeminal neuralgia. J Neurosurg. 2008, 109:185-189.

37. Huang CF, Tu HT, Liu WS, Chiou SY, Lin LY: Gamma Knife surgery used as primary and repeated treatment for idiopathic trigeminal neuralgia. J Neurosurg. 2008, 109:179-184.

38. Oh IH, Choi SK, Park BJ, Kim TS, Rhee BA, Lim YJ: The treatment outcome of elderly patients with idiopathic trigeminal neuralgia: micro-vascular decompression versus Gamma Knife radiosurgery. J Korean Neurosurg Soc. 2008, 44:199-204. 10.3340/jkns.2008.44.4.199

39. Dhople AA, Adams JR, Maggio WW, Naqvi SA, Regine WF, Kwok Y: Long-term outcomes of Gamma Knife radiosurgery for classic trigeminal neuralgia: implications of treatment and critical review of the literature. J Neurosurg. 2009, 111:351-358. 10.3171/2009.2.JNS08977

40. Knafo H, Kenny B, Mathieu D: Trigeminal neuralgia: outcomes after Gamma Knife radiosurgery. Can J Neurol Sci. 2009, 36:78-82.

41. Han JH, Kim DG, Chung HT, et al.: Long-term outcome of gamma knife radiosurgery for treatment of typical trigeminal neuralgia. Int J Radiat Oncol Biol Phys. 2009, 75:822-827. 10.1016/j.ijrobp.2008.11.046

42. Fariselli L, Marras C, De Santis M, et al.: CyberKnife radiosurgery as a first treatment for idiopathic trigeminal neuralgia. Neurosurgery. 2009, 64:96-101.

10.1227/01.NEU.0000341714.55023.8F

43. Adler JR Jr, Bower R, Gupta G, et al.: Nonisocentric radiosurgical rhizotomy for trigeminal neuralgia. Neurosurgery. 2009, 64:84-90. 10.1227/01.NEU.0000341631.49154.62

44. Park SH, Hwang SK, Kang DH, Park J, Hwang JH, Sung JK: The retrogasserian zone versus dorsal root entry zone: comparison of two targeting techniques of gamma knife radiosurgery for trigeminal neuralgia. Acta Neurochir (Wien). 2010, 152:1165-1170. 10.1007/s00701-0100610-0

45. Chen MJ, Shao ZY, Zhang WJ, Wang ZH, Zhang WH, Hu HS: X-knife stereotactic radiosurgery on the trigeminal ganglion to treat trigeminal neuralgia: a preliminary study. Minim Invasive Neurosurg. 2010, 53:223-228. 10.1055/s-0030-1269926

46. Sheehan JP, Ray DK, Monteith S, et al.: Gamma Knife radiosurgery for trigeminal neuralgia: the impact of magnetic resonance imaging-detected vascular impingement of the affected nerve. J Neurosurg. 2010, 113:53-58. 10.3171/2009.9.JNS09196

47. Hayashi M, Chernov M, Tamura N, et al.: Stereotactic radiosurgery of essential trigeminal neuralgia using Leksell Gamma Knife model C with automatic positioning system: technical nuances and evaluation of outcome in 130 patients with at least 2 years follow-up after treatment. Neurosurg Rev. 2011, 34:497-508. 10.1007/s10143-011-0330-9

48. Park SH, Hwang SK: Outcomes of gamma knife radiosurgery for trigeminal neuralgia after a minimum 3-year follow-up. J Clin Neurosci. 2011, 18:645-648. 10.1016/j.jocn.2010.09.007

49. Park YS, Kim JP, Chang WS, Kim HY, Park YG, Chang JW: Gamma knife radiosurgery for idiopathic trigeminal neuralgia as primary vs. secondary treatment option. Clin Neurol Neurosurg. 2011, 113:447-452. 10.1016/j.clineuro.2011.01.006

50. Tuleasca C, Carron R, Resseguier N, et al.: Patterns of pain-free response in 497 cases of 
classic trigeminal neuralgia treated with Gamma Knife surgery and followed up for least 1 year. J Neurosurg. 2012, 117:181-188.

51. Fraioli MF, Strigari L, Fraioli C, Lecce M, Lisciani D: Preliminary results of 45 patients with trigeminal neuralgia treated with radiosurgery compared to hypofractionated stereotactic radiotherapy, using a dedicated linear accelerator. J Clin Neurosci. 2012, 19:1401-1403. 10.1016/j.jocn.2011.11.036

52. Attia A, Tatter SB, Weller M, et al.: CT-only planning for Gamma Knife radiosurgery in the treatment of trigeminal neuralgia: methodology and outcomes from a single institution. J Med Imaging Radiat Oncol. 2012, 56:490-494. 10.1111/j.1754-9485.2012.02403.X

53. Lee JK, Choi HJ, Ko HC, Choi SK, Lim YJ: Long term outcomes of Gamma Knife radiosurgery for typical trigeminal neuralgia-minimum 5-year follow-up. J Korean Neurosurg Soc. 2012, 51:276-280. 10.3340/jkns.2012.51.5.276

54. Flickinger JC Jr, Kim H, Kano H, et al.: Do carbamazepine, gabapentin, or other anticonvulsants exert sufficient radioprotective effects to alter responses from trigeminal neuralgia radiosurgery?. Int J Radiat Oncol Biol Phys. 2012, 83:501-506. 10.1016/j.ijrobp.2012.01.016

55. Lazzara BM, Ortiz O, Bordia R, Witten MR, Haas JA, Katz AJ, Brown JA: Cyberknife radiosurgery in treating trigeminal neuralgia. J Neurointerv Surg. 2013, 5:81-85. 10.1136/neurintsurg-2011-010125

56. Young B, Shivazad A, Kryscio RJ, St. Clair W, Bush HM: Long-term outcome of high-dose Gamma Knife surgery in treatment of trigeminal neuralgia. J Neurosurg. 2013, 119:11661175. 10.3171/2013.1.JNS12875

57. Lee JK, Kim DR, Huh YH, Kim JK, Namgung WC, Hong SH: Long-term outcome of Gamma Knife surgery using a retrogasserian petrous bone target for classic trigeminal neuralgia. Acta Neurochir Suppl. 2012, 116:127-135. 10.1007/978-3-7091-1376-9_20

58. Lucas JT Jr, Nida AM, Isom S, et al.: Predictive nomogram for the durability of pain relief from Gamma Knife radiation surgery in the treatment of trigeminal neuralgia. Int J Radiat Oncol Biol Phys. 2014, 89:120-126. 10.1016/j.ijrobp.2014.01.023

59. Song ZX, Qian W, Wu YQ, et al.: Effect of the Gamma Knife treatment on the trigeminal nerve root in Chinese patients with primary trigeminal neuralgia. Turk Neurosurg. 2014, 24:163169. 10.5137/1019-5149.JTN.6709-12.1

60. Xu Z, Schlesinger D, Moldovan K, et al.: Impact of target location on the response of trigeminal neuralgia to stereotactic radiosurgery. J Neurosurg. 2014, 120:716-724. 10.3171/2013.10.JNS131596

61. Tyler-Kabara EC, Kassam AB, Horowitz MH, et al.: Predictors of outcome in surgically managed patients with typical and atypical trigeminal neuralgia: comparison of results following microvascular decompression. J Neurosurg. 2002, 96:527-531. 10.3171/jns.2002.96.3.0527

62. Ashkan K, Marsh H: Microvascular decompression for trigeminal neuralgia in the elderly: a review of the safety and efficacy. Neurosurgery. 2004, 55:840-850. 10.1227/01.NEU.0000137660.06337.C5

63. Olson S, Atkinson L, Weidmann M: Microvascular decompression for trigeminal neuralgia: recurrences and complications. J Clin Neurosci. 2005, 12:787-789. 10.1016/j.jocn.2005.08.001

64. Zakrzewska JM, Lopez BC, Kim SE, Coakham HB: Patient reports of satisfaction after microvascular decompression and partial sensory rhizotomy for trigeminal neuralgia. Neurosurgery. 2005, 56:1304-1312. 10.1227/01.NEU.0000159883.35957.E0

65. Aryan HE, Nakaji P, Lu DC, Alksne JF: Multimodality treatment of trigeminal neuralgia: impact of radiosurgery and high resolution magnetic resonance imaging. J Clin Neurosci. 2006, 13:239-244. 10.1016/j.jocn.2005.01.009

66. Laghmari M, El Ouahabi A, Arkha Y, Derraz S, El Khamlichi A: Are the destructive neurosurgical techniques as effective as microvascular decompression in the management of trigeminal neuralgia?. Surg Neurol. 2007, 68:505-512. 10.1016/j.surneu.2006.11.066

67. Tarricone R, Aguzzi G, Musi F, Fariselli L, Casasco A: Cost-effectiveness analysis for trigeminal neuralgia: Cyberknife vs microvascular decompression. Neuropsychiatr Dis Treat. 2008, 4:647-652.

68. Bond AE, Zada G, Gonzalez AA, Hansen C, Giannotta SL: Operative strategies for minimizing hearing loss and other major complications associated with microvascular decompression for trigeminal neuralgia. World Neurosurg. 2010, 74:172-177. 10.1016/j.wneu.2010.05.001 
69. Oesman C, Mooij JJ: Long-term follow-up of microvascular decompression for trigeminal neuralgia. Skull Base. 2011, 21:313-322. 10.1055/s-0031-1284213

70. Chakravarthi SP, Ghanta R, Kattimani V: Microvascular decompression treatment for trigeminal neuralgia. J Craniofac Surg. 2011, 22:894-898. 10.1097/SCS.0b013e31821a07b7

71. Chen JCT: Microvascular decompression for trigeminal neuralgia in patients with and without prior stereotactic radiosurgery. World Neurosurg. 2012, 78:149-154.

10.1016/j.wneu.2011.09.029

72. Zhong J, Li ST, Zhu J, et al.: A clinical analysis on microvascular decompression surgery in a series of 3000 cases. Clin Neurol Neurosurg. 2012, 114:846-851.

10.1016/j.clineuro.2012.01.021

73. Sandel T, Eide PK: Long-term results of microvascular decompression for trigeminal neuralgia and hemifacial spasms according to preoperative symptomatology. Acta Neurochir (Wien). 2013, 155:1681-1692. 10.1007/s00701-013-1816-8

74. Reddy VK, Parker SL, Patrawala SA, et al.: Microvascular decompression for classic trigeminal neuralgia: determination of minimum clinically important difference in pain improvement for patient reported outcomes. Neurosurgery. 2013, 72:749-754. 10.1227/NEU.0b013e318286fad2

75. Shibahashi K, Morita A, Kimura T: Surgical results of microvascular decompression procedures and patient's postoperative quality of life: review of 139 cases. Neurol Med Chir (Tokyo). 2013, 53:360-364.

76. Sarnvivad P, Bumpenboon A, Chumnanvej S: Retrospective long term outcome following microvascular decompression surgery in Thai patients with trigeminal neuralgia. J Med Assoc Thai. 2013, 96:801-806.

77. Perez C, Navarro A, Saldana MT, Martinez S, Rejas J: Patient-reported outcomes in subjects with painful trigeminal neuralgia receiving pregabalin: evidence from medical practice in primary care settings. Cephalalgia. 2009, 29:781-790.

78. Spatz AL, Zakrzewska JM, Kay EJ: Decision analysis of medical and surgical treatments for trigeminal neuralgia: how patient evaluations of benefits and risks affect the utility of treatment decisions. Pain. 2007, 131:302-310. 10.1016/j.pain.2007.02.009

79. Lega BC, Danish SF, Malhotra NR, Sonnad SS, Stein SC: Choosing the best operation for chronic subdural hematoma: a decision analysis. J Neurosurg. 2010, 113:615-621. 10.3171/2009.9.JNS08825

80. Whitmore RG, Urban C, Church E, Ruckenstein M, Stein SC, Lee JY: Decision analysis of treatment options for vestibular schwannoma. J Neurosurg. 2011, 114:400-413. 10.3171/2010.3.JNS091802

81. van de Graaf ES, van Kempen-du Saar H, Looman CW, Simonsz HJ: Utility analysis of disability caused by amblyopia and/or strabismus in a population-based, historic cohort. Graefes Arch Clin Exp Ophthalmol. 2010, 248:1803-1807. 10.1007/s00417-010-1457-z

82. Hatt SR, Leske DA, Holmes JM: Responsiveness of health-related quality-of-life questionnaires in adults undergoing strabismus surgery. Ophthalmology. 2010, 117:23222328. 10.1016/j.ophtha.2010.03.042

83. Samsa GP, Reutter RA, Parmigiani G, et al.: Performing cost-effectiveness analysis by integrating randomized trial data with a comprehensive decision model: application to treatment of acute ischemic stroke. J Clin Epidemiol. 1999, 52:259-271.

84. Sivakanthan S, Van Gompel JJ, Alikhani P, et al.: Surgical management of trigeminal neuralgia: use and cost-effectiveness from an analysis of the Medicare Claims Database. Neurosurgery. 2014, 75:220-226. 10.1227/NEU.0000000000000430

85. Wang DD, Ouyang D, Englot DJ, et al.: Trends in surgical treatment for trigeminal neuralgia in the United States of America from 1988 to 2008. J Clin Neurosci. 2013, 20:1538-1545. 10.1016/j.jocn.2012.12.026

86. Tatli M, Satici O, Kanpolat Y, Sindou M: Various surgical modalities for trigeminal neuralgia: literature study of respective long-term outcomes. Acta Neurochir (Wien). 2008, 150:243-255. 10.1007/s00701-007-1488-3

87. Meybodi AT, Habibi Z, Miri M, Tabatabaie SA: Microvascular decompression for trigeminal neuralgia using the 'Stitched Sling Retraction' technique in recurrent cases after previous microvascular decompression. Acta Neurochir (Wien). 2014, 156:1181-1187. 10.1007/s00701014-2092-y

88. Barker FG 2nd, Jannetta PJ, Bissonette DJ, Jho HD: Trigeminal numbness and tic relief after microvascular decompression for typical trigeminal neuralgia. Neurosurgery. 1997, 40:39-45. 
89. Bederson JB, Wilson CB: Evaluation of microvascular decompression and partial sensory rhizotomy in 252 cases of trigeminal neuralgia. J Neurosurg. 1989, 71:359-367.

10.3171/jns.1989.71.3.0359

90. Sekula RF, Marchan EM, Fletcher LH, Casey KF, Jannetta PJ: Microvascular decompression for trigeminal neuralgia in elderly patients. J Neurosurg. 2008, 108:689-691.

10.3171/JNS/2008/108/4/0689

91. Bohman LE, Pierce J, Stephen JH, Sandhu S, Lee JY: Fully endoscopic microvascular decompression for trigeminal neuralgia: technique review and early outcomes. Neurosurg Focus. 2014, 37:18. 10.3171/2014.7.FOCUS14318

92. Regis J, Metellus P, Hayashi M, Roussel P, Donnet A, Bille-Turc F: Prospective controlled trial of gamma knife surgery for essential trigeminal neuralgia. J Neurosurg. 2006, 104:913-924. 10.3171/jns.2006.104.6.913

93. Brisman R: Gamma knife surgery with a dose of 75 to 76.8 Gray for trigeminal neuralgia . J Neurosurg. 2004, 100:848-854. 10.3171/jns.2004.100.5.0848

94. Pollock BE, Phuong LK, Foote RL, Stafford SL, Gorman DA: High-dose trigeminal neuralgia radiosurgery associated with increased risk of trigeminal nerve dysfunction. Neurosurgery. 2001, 49:58-64.

95. Pollock BE, Phuong LK, Gorman DA, Foote RL, Stafford SL: Stereotactic radiosurgery for idiopathic trigeminal neuralgia. J Neurosurg. 2002, 97:347-353. 10.3171/jns.2002.97.2.0347

96. Massager N, Lorenzoni J, Devriendt D, et al.: Gamma knife surgery for idiopathic trigeminal neuralgia performed using a far-anterior cisternal target and a high dose of radiation. J Neurosurg. 2009, 111:597-605.

97. Flickinger JC, Pollock BE, Kondziolka D, et al.: Does increased nerve length within the treatment volume improve trigeminal neuralgia radiosurgery? A prospective double-blind, randomized study. Int J Radiat Oncol Biol Phys. 2001, 51:449-454.

98. Morbidini-Gaffney S, Chung CT, Alpert TE, et al.: Doses greater than 85 Gy and two isocenters in Gamma Knife surgery for trigeminal neuralgia: updated results. J Neurosurg. 2011, 15:107111.

99. Parmar M, Sharma N, Modgill V, Naidu P: Comparative evaluation of surgical procedures for trigeminal neuralgia. J Maxillofac Oral Surg. 2013, 12:400-409. 10.1007/s12663-012-0451-x

100. Brezovich IA, Wu X, Duan J, et al.: End-to-end test of spatial accuracy in Gamma Knife treatments for trigeminal neuralgia. Med Phys. 2014, 41:111703. 10.1118/1.4896819

101. Tuleasca C, Carron R, Resseguier N, et al.: Repeat Gamma Knife surgery for recurrent trigeminal neuralgia: long-term outcomes and systematic review. J Neurosurg. 2014, 121:210221.

102. Hasegawa T, Kondziolka D, Spiro R, Flickinger JC, Lunsford LD: Repeat radiosurgery for refractory trigeminal neuralgia. Neurosurgery. 2002, 50:494-502.

103. Cruccu G, Gronseth G, Alksne J, et al.: AAN-EFNS guidelines on trigeminal neuralgia management. Eur J Neurol. 2008, 15:1013-1028. 10.1111/j.1468-1331.2008.02185.x

104. Little AS, Shetter AG, Shetter ME, Kakarla UK, Rogers CL: Salvage Gamma Knife stereotactic radiosurgery for surgically refractory trigeminal neuralgia. Int J Radiat Oncol Biol Phys. 2009, 74:522-527. 10.1016/j.ijrobp.2008.08.048

105. Maesawa S, Salame C, Flickinger JC, Pirris S, Kondziolka D, Lunsford LD: Clinical outcomes after stereotactic radiosurgery for idiopathic trigeminal neuralgia. J Neurosurg. 2001, 94:1420. 10.3171/jns.2001.94.1.0014

106. Régis J, Tuleasca C, Resseguier N, et al.: Long-term safety and efficacy of Gamma Knife surgery in classical trigeminal neuralgia: a 497-patient historical cohort study. J Neurosurg. 2016, 124:1079-1087.

107. Holland M, Noeller J, Buatti J, et al.: The cost-effectiveness of surgery for trigeminal neuralgia in surgically naive patients: a retrospective study. Clin Neurol Neurosurg. 2015, 137:34-37. 10.1016/j.clineuro.2015.06.011

108. Zakrzewska JM, Lopez BC: Quality of reporting in evaluations of surgical treatment of trigeminal neuralgia: recommendations for future reports. Neurosurgery. 2003, 53:110-120.

109. Pan HC, Sheehan J, Huang CF, et al.: Quality-of-life outcomes after Gamma Knife surgery for trigeminal neuralgia. J Neurosurg. 2011, 15:191-198.

110. Lee JY, Chen HI, Urban C, et al.: Development of and psychometric testing for the Brief Pain Inventory-Facial in patients with facial pain syndromes. J Neurosurg. 2010, 113:516-523. 10.3171/2010.1.JNS09669 